\title{
LA FRONTERA AMAZÓNICA EN EL PERÚ DEL SIGLO XVIII. UNA REPRESENTACIÓN DESDE LA ILUSTRACIÓN
}

\author{
Víctor Peralta Ruiz \\ CSIC, Madrid
}

\section{Introducción}

El objetivo de este trabajo es reflexionar el proceso de representación de la frontera andino-amazónica peruana en la segunda mitad del siglo XVIII. Por representación se comprende los sistemas de percepción, juicio y construcción de significados que generan los discursos, imágenes y actitudes individuales o colectivas sobre una realidad social'. En un reciente estado de la cuestión Frederica Barclay ha destacado la extrema marginalidad de los estudios andino-amazónicos en el quehacer historiográfico. Esta autora señala que los escasos esfuerzos por entender las formas y alcances de la penetración de las instituciones coloniales en las distintas regiones que componen la amazonía andina, es decir la zona que abarca las cuencas alta y baja del río Amazonas, han estado metodológicamente delimitados por el estudio obsesionado de las rebeliones andinas $^{2}$. Barclay se refiere en concreto a la fascinación que en los historiadores y antropólogos provocó el estudio de la rebelión de Juan Santos Atahualpa en 1742 en la región central amazónica debido al carácter mesiánico de su liderazgo, a la envergadura de su proyección regional y al prolongado período de duración del movimiento ${ }^{3}$. Sólo un reciente estudio ha tratado polémicamente

1. Chartier, R., El mundo como representación. Barcelona, 1992.

2. Barclay Rey de Castro, F., "Olvido de una historia. Reflexiones acerca de la historiografía andino-amazónica". Revista de Indias 223 (2001), p. 503.

3. Cronológicamente el estudio de esta rebelión ha tenido los siguientes hitos: Loayza, F.A., Juan Santos el invencible. Lima, 1943; Varese, S., La sal de los cerros. Una aproximación al mundo campa. Lima, 1968; Castro Arenas, M., La rebelión de Juan Santos. Lima, 1973; Flores Galindo, A., Buscando un inca: Identidad y utopía en los Andes. Lima, 1988; Zarzar, A. Apo 
de encuadrar esa como una insurrección política ${ }^{4}$. Pero lo que interesa resaltar de todos estos enfoques es que la rebelión del autoproclamado "inca" Juan Santos Atahualpa demarca el antes y después en la forma de aproximarse al estudio de la frontera andino-amazónica. En efecto, la historiografía señala dos cortes cronológicos fundamentales en el proceso de dominación española del oriente amazónico en el siglo XVIII. El primer corte comprende el período iniciado con las ordenanzas del virrey Francisco de Toledo en 1570 que en relación con la Amazonía interrumpió las expediciones militares y auspició el proceso de conversión religiosa en las que tuvieron un papel destacado los jesuitas, los franciscanos, y los dominicos. Este corte concluyó en 1742 con el alzamiento de Juan Santos Atahualpa y los numerosos grupos amazónicos de etnia arawak que le secundaron que directamente afectó a las misiones franciscanas establecidas en la región central peruana que comprende las provincias de Tarma, Jauja y Huánuco. El segundo corte, por tanto, se delimita entre los años de 1742 y 1821 y se caracteriza como el del repliegue general de la frontera con la desconexión mercantil entre las regiones de la sierra y de la selva, el descalabro de las conversiones religiosas, la expulsión de los jesuitas en 1767 que afectó a las misiones amazónicas de Mainas y Chiquitos y el fracaso de la reconquista militar y religiosa de la amazonía ${ }^{5}$. Esto fue así desde el punto de vista de la sociedad dominante. Pero según una interpretación antropológica, que asume la versión de los grupos subalternos, con el cierre del acceso a la selva como resultado de la rebelión de 1742 "Ios nativos amazónicos lograron lo que buscaban, al menos por un cierto tiempo: deshacerse del dominio misional y su secuela de epidemias e imposiciones normativas contrarias a su tradición cultural" ${ }^{\prime \prime}$.

Las fuentes utilizadas por los investigadores para analizar la frontera andinoamazónica peruana en el siglo XVIII han procedido fundamentalmente de los testimonios históricos elaborados por los misioneros franciscanos, entre los que destacan los relatos de Fernando de San José, Domingo García, Manuel del Santo, José Amich, Placido de Pinedo, Miguel de Salcedo y Francisco Rodríguez Tena. Como complemento de estas fuentes se han utilizado los informes oficiales de las

Capac Huayna Jesús Sacramentado. Mito, utopía y milenarismo en el pensamiento de Juan Santos Atahualpa. Lima, 1989; Santos Granero, F., "Anticolonialismo, mesianismo y utopía en la sublevación de Juan Santos Atahualpa, siglo XVIII", Santos Granero, F. (comp.). Opresión colonial y resistencia indígena en la Alta Amazonía, Quito, 1992, pp. 103-132; Mateos FernándezMaquieira, S., "Juan Santos Atahualpa. Un movimiento milenarista en la selva". Amazonía Peruana 22 (1992), pp. 47-60.

4. Santamaría, D. J., "La rebelión de Juan Santos Atahuallpa en la selva central peruana (1742-1756). ¿Movimiento religioso o insurrección política?". Boletín Americanista 57 (2007), pp. 233-256.

5. García Jordán, P., "La frustrada reconquista de la Amazonía andina (1742-1821)", García Jordán, P. et al. (coords.), Las raíces de la memoria. América Latina Ayer y Hoy. Quinto Encuentro Debate. Barcelona, 1996, p. 427.

6. Zarzar, Apo Capac Huayna, p. 34. 
expediciones militares enviadas a la región como, por ejemplo, la que comandó Joseph de Llamas en 1751 a la región de Quimiri. Por último, han sido también de suma utilidad los informes incluidos en sus respectivas relaciones de gobierno por los virreyes conde de Superunda, Amat y Junient, Guirior y Gil de Taboada y Lemus. En cambio, casi no han sido utilizados los testimonios confeccionados sobre la amazonía por los miembros de las expediciones científicas y por otros escritores adscritos al movimiento ilustrado. Estas son las fuentes alrededor del cual este estudio propone realizar una reflexión sobre la representación de la frontera andino-amazónica en la segunda mitad del siglo XVIII. Se abordará en concreto los testimonios sobre esta región vertidos por Charles Marie de la Condamine, Antonio de Ulloa, Jorge Juan, José Eusebio Llano Zapata, Cosme Bueno, Hipólito Ruiz, José Pavón, Alejandro Malaspina y José Ignacio de Lecuanda.

\section{La Condamine y la Amazonía}

El científico francés Charles Marie de la Condamine arribó a la Audiencia de Quito en 1736 en calidad de integrante de la misión geodésica hispano-francesa a la que se encomendó la misión de determinar el valor de un grado del meridiano terrestre en las proximidades de la línea equinoccial. Culminada esta misión en 1744 La Condamine decidió emprender su retorno a Europa navegando por la ruta del río Amazonas que cruza la gobernación y misiones de Mainas y prosigue su curso por el nordeste brasileño hasta desembocar en el océano Atlántico. A lo largo de este recorrido La Condamine emprendió una investigación científica con el propósito de elaborar un mapa del curso del río más importante y caudaloso de la América del Sur. Estas observaciones particulares del viajero ilustrado francés fueron publicadas en 1745 primero en español y luego en francés con el título de Relación abreviada de un viaje hecho por el interior de la América Meridional, y un resumen del mismo fue leído en la Academia de Ciencias de París el 7 de noviembre de 1745.

La sensación que deja la lectura de la Relación abreviada es que el objeto de interés de La Condamine estuvo centrado fundamentalmente en describir y medir el gran río amazónico. Los instrumentos de medición científica que transportó estuvieron orientados a medir "su anchura y profundidad, su caudal y velocidad, la situación de las desembocaduras y afluentes, la variación de la aguja magnética, la formación de mareas o los peligros de la navegación"7. Pero esta obsesión científica no impidió que su observación también en ocasiones se dirigiera a comentar el grado de asimilación cultural o "civilización" de los distintos poblados nativos del entorno que recorrió. De los jíbaros destaca La Condamine que en algún tiempo fueron cristianizados por los jesuitas pero luego se alzaron y "desde este tiempo, retraídos en montes inaccesibles, permanecen

7. Lafuente, A. y Estrella, E., "La Condamine en la América Meridional". La Condamine, C. M., Viaje a la América Meridional por el río de las Amazonas. Barcelona, 1986, p. 8. 
independientes y estorban la navegación de este río, por donde se podría llegar cómodamente en menos de ocho días desde las cercanías de Loja y Cuenca, de donde yo salí por tierra hacía dos meses" ${ }^{\prime \prime}$. De los yameos escribe que la comprensión de su idioma es de una dificultad insuperable por su modo de pronunciar guturalmente las palabras, encuentra que tienen vocablos que no se pueden escribir con menos de diez sílabas, y por ejemplo "poetararorincouro$\mathrm{ac}^{\prime \prime}$ entre ellos significa el número tres. La Condamine en un evidente gesto de desprecio añade que "afortunamente para los que tratan con ellos, su aritmética no llega más allá" amplio relato destaca que esta es una nación que tiene por extraña costumbre comprimir la cabeza de sus hijos recién nacidos, pero que su lengua es fácil de comprender como la de los yameos. La Condamine confiesa que incluso se ha aventurado a recopilar en un vocabulario las voces omaguas más utilizadas. También, tiene palabras de elogio para la misión jesuita de Pevas en las orillas del Marañón que reúne a varias naciones que hablan sus lenguas particulares. No obstante, no omite expresar su opinión de que "la mayor parte de los nuevos habitantes de Pevas no son aún cristianos, son salvajes sacados recientemente de la espesura de los bosques. No se trata hasta ahora sino de convertirlos en hombres civilizados, lo cual no es tarea insignificante"10.

El viajero francés pese a su ilustración no se resistió a tratar dos de los temas más recurrentemente discutidos en Europa desde la época de la conquista como fueron la supuesta existencia de las míticas amazonas y la búsqueda de ese paraíso en la tierra Ilamado El Dorado. En cuanto a las amazonas, La Condamine prestó credibilidad a los distintos informantes que le hicieron mención de la presencia de esta "república de mujeres belicosas" a pesar de nunca haberlas visto. También aventura señalar que las amazonas modernas se refugian en un paraje del centro de la Guayana en donde ni los portugueses del Pará ni los franceses de Cayana ni los holandeses de Surinam se atreven a penetrar. La Condamine acepta esta posibilidad a pesar de dar poco crédito a los testimonios de los nativos porque considera en general a los indios americanos como mentirosos, crédulos y amantes de lo fabuloso. Pero para él es un hecho significativo que no teniendo noticia en estos lugares de las míticas amazonas asiáticas, resulta admirable la difusión de la certeza de su existencia entre pueblos sin contacto histórico entre sí: "ise puede creer que salvajes de comarcas alejadas se hayan puesto de acuerdo para imaginar sin ningún fundamento, el mismo hecho, y que esta pretendida fábula haya sido adaptada tan uniforme y universalmente en Maynas, en Pará, en Cayena y en Venezuela, entre tantos pueblos

8. La Condamine, C. M., Relación abreviada de un viaje hecho por el interior de la América Meridional, desde la costa del Mar del Sur hasta las costas del Brasil y de la Guayana, siguiendo el curso del río de las Amazonas (1745). Madrid, 1921, p. 31.

9. Condamine, Relación abreviada, p. 48.

10. Condamine, Relación abreviada, p. 58. 
que no se entienden ni tienen ninguna comunicación?"1". La Condamine considera que tal como ocurrió con los testimonios vertidos por Vespucio, Schmidel, Orellana, Raleigh y Acuña en siglos anteriores, su deseo era dejar al libre albedrío de sus lectores discernir sobre la existencia o no de las amazonas.

Como complemento del interés de La Condamine por describir el curso del río Amazonas también se hallan sus breves observaciones acerca de los reinos animal, vegetal y mineral. Su relato comienza con la descripción de los "peces raros" que viven en el Amazonas. Se detiene especialmente en la llamada vaca marina o pez buey, el más grande de estos peces, que vio en el poblado de San Pablo de Omaguas y de la que hizo hasta un dibujo. También describe algunos mamíferos como el "cuadrúpedo raro" denominado danta, pero también hace mención del coatí, el tigre, el cocodrilo y el mono. Incluye además breves anotaciones sobre las serpientes de las que destaca el "monstruo anfibio" conocido como Mama-Yacu o Madre de Agua que es capaz de devorar venados enteros y hasta seres humanos. De las aves que más le llaman la atención está el picaflor de Quito, el Contur del Perú y el Churuari en Mainas, este último una especie de buitre. Menos intereses presta La Condamine a la descripción de la flora. Por ejemplo, se refiere a las virtudes purgativas del floripondio y la curupa que conocen los omaguas. Habla también del ungurave una fruta del que se extrae una goma. También destaca las virtudes curativas de la andiroba, la utilidad como alumbre del copal y la virtud elástica de la resina conocida como cahuchu. Por último, en relación con los minerales Ilama poderosamente su atención unas piedras de tonalidad verde que también se llaman "piedras de las Amazonas" que tendrían la virtud de curar la epilepsia.

Cuando La Condamine plasmó estas descripciones de la frontera amazónica en la región de Mainas en su Relación abreviada hacía dos años que había estallado la rebelión de Juan Santos Atahualpa en la selva central del virreinato del Perú. Pero esta convulsión no parecía haber afectado a las poblaciones nativas cuyo adoctrinamiento dependía de los misioneros jesuitas y cuyo gobierno político dependía de la gobernación de Mainas que por entonces formaba parte de la audiencia de Quito. Ello no significa que la alarma ante el peligro de un contagio del movimiento rebelde proveniente del sur no se hubiese activado. En 1747 el maestre de campo Francisco Matías de Rioja, justicia mayor de Mainas, hizo una petición a la real audiencia de Quito para que se le proveyera de armas y pertrechos para hacer frente a los rumores que señalaban la proximidad del "indio inga fingido"12. Pero los fiscales no compartieron esa sensación de peligro y sólo autorizaron a esta autoridad a que se desterrase fuera de la provincia a los "indios incorregibles y perniciosos". Esto último indicaba la existen-

11. Condamine, Relación abreviada, p. 73.

12. Porras, M. E., La gobernación y el obispado de Mainas, siglos XVII y XVIII. Quito, 1987, p. 46. 
cia de problemas en la conversión religiosa y la asimilación cultural de los poblados nativos de las misiones jesuitas. La expulsión de esta orden religiosa en 1767 de esta provincia supuso el reemplazo de estos misioneros por religiosos seculares que por su inexperiencia tuvieron muchas dificultades para defender el avance fronterizo logrado por los jesuitas en los dos siglos anteriores.

\section{Los ilustrados ante la rebelión de Juan Santos Atahualpa y la pérdida de la amazonía andina}

Los jóvenes marinos y científicos españoles Jorge Juan y Antonio de Ulloa formaron parte de la expedición geodésica de medición del meridiano que también integraron los científicos franceses Luis Godin, Pierre Bouguer y La Condamine. Pero la permanencia de Juan y Ulloa en la América Meridional se prolongó más allá del período de actividad de esa misión científica que concluyó en 1744. El motivo principal de esta estancia extraordinaria fue que ambos fueron convocados a Lima por el virrey marqués de Villagarcía para asesorarle en materia de defensa como resultado de la guerra que había estallado entre España e Inglaterra en 1739. En esta coyuntura además Juan y Ulloa emprendieron un recorrido científico por algunas regiones del virreinato del Perú de la que dejaron dos testimonios escritos, la Relación histórica del viaje a la América meridional escrita por Ulloa y las Observaciones astronómicas y físicas en los Reynos del Perú redactada por Juan. Ambas obras fueron publicadas en Madrid en 1748. Para los propósitos que se persigue este estudio interesa detenerse en el "Resumen histórico del origen y sucesión de los incas y demás soberanos del Perú con noticias de los sucesos más notables en el reinado de cada uno" que fue incluido como apéndice del segundo tomo de la Relación histórica, ya que en un pasaje del mismo hay una extensa referencia a la rebelión de Juan Santos Atahualpa. Es conocido el desprecio racial que Juan y Ulloa sentían en general hacia las poblaciones indígenas, de los que por otro lado apenas hacen mención en sus escritos. Ambos comulgaban con los prejuicios vertidos por La Condamine de que aparte de su inferioridad natural frente al hombre blanco los indígenas eran perezosos, mentirosos y poco de confiar. Esa es la actitud con que Ulloa iba a abordar la rebelión de los indígenas de la amazonía central peruana que cuando su obra salió publicada estaba en su pleno apogeo y amenazaba con convertirse en un problema insoluble para el gobierno virreinal.

Si bien Ulloa y Juan no visitaron en el transcurso de su viaje por el Perú las regiones colindantes con la región central amazónica adscritas a las provincias de Tarma y Jauja, si tuvieron especial cuidado en recoger una serie de testimonios para incorporar en su relato lo que venía ocurriendo con los llamados "indios chunchos" que se rebelaron en las misiones franciscanas y que proclamaron a su líder como rey dada su supuesta condición de descendiente de los antiguos monarcas incas. Consideraban que el objetivo de Juan Santos Atahualpa, a quien nunca mencionaban por este nombre sino como "el sublevado", era "recuperar 
aquel imperio y poner a los indios en el pie que estaban cuando reinaban los incas $^{\prime \prime 13}$. Lo alarmante para ambos expedicionarios es que no sólo la rebelión había obligado a los misioneros franciscanos a abandonar sus establecimientos y replegarse a la costa, sino que la frontera entre los Andes y la Amazonía había experimentado un repliegue en favor de la segunda con el peligroso significado que ello tenía en el avance de la rusticidad que era el antónimo por excelencia del concepto de civilización en aquella época ${ }^{14}$. La principal consecuencia de ello era el retroceso de los indígenas al estado primigenio de la humanidad o "salvajismo". Juan y Ulloa se referían en concreto a la alarmante pérdida de amplias porciones territoriales del oriente de las provincias de Tarma y Jauja colindantes con la cordillera de los Andes entre los ríos Paucartambo y Tarma.

En la Relación histórica se hace un resumen del fracaso de todas las empresas militares que el virrey marqués de Villagarcía y las autoridades de Tarma impulsaron para intentar contener el contagio social y el avance de las partidas rebeldes de Santos Atahualpa. Se destaca en especial la ofensiva conjunta emprendida por las tropas reales y una milicia de indios movilizada por el cacique de Tarma con la autorización especial de Villagarcía. Ulloa señala que el virrey aprobó esta iniciativa confiando en que los indios que movilizara el cacique tendrían la ventaja sobre las tropas de españoles y mestizos de desenvolverse mejor en un medio geográfico de difícil dominio y acceso. Pero la ofensiva no sólo fracasó y provocó numerosas bajas en las tropas del virrey sino que "la gloria de este suceso aumentó en los indios el atrevimiento; y adelantándose hacia Pasco, llegaron a 12 leguas de esta población y entraron en la de Villacampa que sólo dista de Lima 40 leguas"15. La posibilidad de que los rebeldes de Santos Atahualpa tomasen la estratégica ciudad serrana de Pasco, una región especializada en la producción de plata, obligó a los oficiales reales a preparar un plan para evacuar la ciudad y así salvaguardar las cajas reales. Pero la ofensiva comandada por Benito Troncoso, corregidor de la vecina Jauja, contuvo el avance de los rebeldes y logró que los indios de la amazonía se replegasen a las montañas. Algo que Ilamó poderosamente la atención de Ulloa en esta contienda fue la parsimonia y la constancia con que los indígenas se tomaban sus luchas. Con relación a la primera, daba crédito al testimonio de un indígena capturado de que la rebelión se había preparado con treinta años de antelación y, en lo que se refiere a la segunda, comentaba la poca sensibilidad que los alzados sentían por sus muertos porque por principio "en las batallas exponen las vidas bárbaramente"116.

13. Ulloa, A. de, Relación histórica del viaje a la América Meridional. Madrid, 1748, t. II, p. CLXIII.

14. Peralta Ruiz, V., "De rústicos a civilizados. El concepto de civilidad en tres historias de la América Meridional". Histórica XXX-1 (2006), pp. 137-163.

15. Ulloa, Relación histórica, t. II, p. CLXVI.

16. Ulloa, Relación histórica, t. II, p. CLXVII. 
Ulloa reconoció que la posibilidad de acabar con la sublevación era remota debido a que los rebeldes usaban como un arma a su favor su privilegiado conocimiento de la montaña, geografía a la que habían convertido en un refugio seguro e impenetrable. Por eso justificó que el gobierno español se resignara a plantear en adelante la guerra no en términos ofensivos sino defensivos con el objeto de que la frontera bajo dominio español no se siguiese estrechando a favor de los rebeldes amazónicos: "determinó (el virrey) seguir el partido de que se pusiese toda la atención en contenerlos para que no pudiesen salir de los países montañosos, incultos o no habitados por los españoles a los que son pertenecientes de las otras provincias sus circunvecinas, siendo las faldas orientales de la cordillera real de los Andes división y lindero de unos y otros..." ${ }^{\prime 17}$.

Para afianzar esta meta los corregidores de Tarma y Jauja formaron en 1743 una milicia con la que recuperaron los pueblos de Quimiri y Chanchamayo y establecieron dos fuertes bien pertrechados. Pero vana fue esta iniciativa porque el fuerte de Quimiri gobernado por Francisco Troncoso al año siguiente se volvió a perder tras un nuevo asedio al que fue sometido por los rebeldes de Santos Atahualpa.

El relato incluido por Ulloa culminaba con una sorprendente referencia a uno de los pedidos de los ocasionales embajadores que envió Santos Atahualpa a Tarma con relación a la presencia de la religión católica en la amazonía. Se trataba de promover en su nueva sociedad utópica que "se ordenasen los indios y ocupasen las dignidades eclesiásticas" y que se estableciesen escuelas de primera enseñanza en donde se pudiesen instruir los indígenas que iban a seguir la carrera eclesiástica. En ambos casos a la única orden religiosa a la que se admitiría sería a la Compañía de Jesús "para que fuesen sus curas, les dijesen misa y enseñasen, dando por razón de esta su particular atención la de que estos padres no llevan en sus misiones otro fin que el de ensalzar la religión y hacer que brillase el culto del verdadero Dios"18. Ulloa no dio crédito a este supuesto pedido y lo consideró como un ardid del líder indígena para ganarse la confianza de los indios de la sierra, ya que pensaba que la verdadera intención de éste era imponer un culto idolátrico en las regiones que llegara a dominar. Pero si se toma en cuenta el contexto religioso de la época marcado por el debate escolástico entre franciscanos y jesuitas, y las luchas entre ambas órdenes por influir en el poder político en el que los franciscanos se estaban llevando la peor parte, se puede advertir una coincidencia entre lo que Santos Atahualpa proponía y el avance logrado por las nociones de pactismo y tiranicidio impulsadas por los jesuitas en las zonas rurales del virreinato antes de que Carlos III dispusiese la expulsión de la orden ${ }^{19}$. Lo que resulta paradójico es que no fueron los jesuitas sino los fran-

17. Ulloa, Relación histórica, t. II, p. CLXVIII.

18. Ulloa, Relación histórica, t. II, p. CLXXVI.

19. Peralta Ruiz, V., "Tiranía o buen gobierno. Escolasticismo y criticismo en el Perú del siglo XVIII", Walker, C. (comp.), Entre la retórica y la insurgencia: las ideas y los movimientos sociales en los Andes, siglo XVIII. Cuzco, 1996, pp. 72-73. 
ciscanos, es decir los misioneros más perjudicados por la rebelión de 1742, quienes en 1750 hicieron suyas las demandas de Santos Atahualpa y las incluyeron en dos memoriales, uno escrito en español y el otro en latín dirigidos, respectivamente, al monarca español y al Papa. En efecto, la Exclamación reivindicacionista de fray Calixto de Tupac Inca y el Planctus Indorum de fray Isidoro de Cala fueron trasladados por sus autores a Madrid. En ambos escritos junto a las denuncias de agravio contra los indios por parte de las autoridades españolas y los eclesiásticos seculares y regulares, se pedía que los indígenas pudiesen ejercer como sacerdotes. Pero finalmente ambas obras fueron confiscadas en esa ciudad y sus autores condenados a penas de reclusión. Si esto es así, esta claro que resultó fallido el objetivo de los dos franciscanos de utilizar en su favor las demandas de Santos Atahualpa, a quien en lugar de este sobrenombre denominaban Huayna Capac Inca, para impulsar una nueva política misionera en la amazonía con la anuencia de los grupos amazónicos en rebelión.

Al comenzar la segunda mitad del siglo XVIII los franciscanos fueron en gran parte responsabilizados de la pérdida de la Amazonía central por el virrey conde de Superunda, quien no sólo fue bastante crítico con ellos sino que incluso fue partidario de que las misiones a cargo de éstos fuesen secularizadas ${ }^{20}$. También Jorge Juan y Antonio de Ulloa en sus Noticias secretas de América, un informe político que ambos redactaron para uso reservado de la monarquía hispánica, atribuyeron a la indisciplina y relajamiento moral de esta orden religiosa algunos de los principales males del virreinato del Perú. Además consideraban que las misiones franciscanas en la amazonía tenían la debilidad de no contar con personas idóneas y con vocación de sacrificio para adoctrinar a los indígenas. Por el contrario, ambos elogiaban la labor de los misioneros jesuitas en la circunscripción quiteña de Mainas que se mantenían tranquilas. Por eso recomendaron a la Corona que el beneficio de la conversión de los indios de toda la amazonía se confiara en adelante a la Compañía de Jesús por su "fervor constante para permanecer en tales empresas sin que la inconstancia de los indios los desaliente" ${ }^{\prime 21}$. En ese sentido, Juan y Ulloa también valoraron la habilidad y la persuasión esgrimida por los miembros de esta orden para contener el avance de los portugueses en dicha región por lo que a su juicio merecían el auspicio de la Corona para emprender sus tareas de adoctrinamiento en nuevas circunscripciones del Perú.

Pese a que las noticias oficiales sobre la actuación de Juan Santos Atahualpa se interrumpieron en 1756, sospechando los historiadores que por esa fecha este líder indígena probablemente falleció, no hubo intentos por parte de los gobiernos virreinales de emprender una ofensiva militar sobre la frontera andino-amazónica en la región central peruana. Más bien se mantuvo la táctica

20. Andrien, K., "Secularization and the Struggles over Clerical Reform in Bourbon Peru, 1746-1773", International Worshop "Enlightened Reform in Southern Europe and its Atlantic Colonies, c. 1750-1830". Cambridge 2007.

21. Juan, J. y Ulloa, A. de, Noticias secretas de América. Londres, 1826, p. 379. 
defensiva y de práctico abandono de la región. De esa circunstancia se hizo eco el cosmógrafo mayor Cosme Bueno quien en su informe anual titulado El Conocimiento de los Tiempos en referencia a la situación de la provincia de Tarma perteneciente al obispado de Lima señala: "Desde el año de 1742, con el motivo de la sublevación de los indios chunchos de la montaña, y pérdida de una población, que había dentro nombrada Huancabamba, que era curato, y destrucción de otros, no se saca de aquellos parajes casi nada de lo mucho con que se abastecía esta provincia como maderas, frutos, coca y algunas semillas. Hay en esta provincia algunos fuertes para contener a los indios levantados y se mantiene la tropa para este efecto" ${ }^{\prime 22}$.

Antes de que el cosmógrafo Bueno hiciera esta afirmación, concretamente en 1761, el ilustrado limeño José Eusebio Llano Zapata culminaba en Cádiz su proyecto de escribir una historia natural del Perú que tituló Memorias histórico, físicas, crítico, apologéticas de la América Meridional, aunque la misma finalmente no se publicó al no obtener el favor real para su edición. La historia natural de Llano Zapata no constituyó una mera descripción de la naturaleza sino que su función última fue proporcionar un inventario de las riquezas minerales, vegetales y animales antes desconocidas y las posibilidades de su explotación. Llano Zapata lamentaba que el repliegue de la amazonía en la región central peruana supusiese la pérdida de una serie de bienes que serían de suma utilidad económica para las arcas reales. A pesar de que el ilustrado limeño nunca visitó la región de Tarma en su obra este menciona que el Cerro de la Sal, que había caído en manos rebeldes, albergaba ricas minas de oro "cuyos metales según tengo noticia, ocultamente han beneficiado muchos" ${ }^{\prime 23}$. Tal afirmación era el producto de un mito forjado en el siglo XVII que resultó ser falso ya que el Cerro de la Sal sólo contenía canteras de salinas que era un bien muy apreciado por las etnias amazónicas. No obstante ello, Llano Zapata propuso a la Corona la reconquista militar de esta región con el propósito de lograr la explotación de ese cerro y de los lavaderos de oro que había en sus alrededores según se lo habían manifestado los franciscanos. El ilustrado limeño abrigó además la esperanza de que obligando a los naturales a trabajar en las minas y los lavaderos "se podrá facilitar la conversión de tantos infieles y apostatas".

Llano Zapata se mostró convencido de que la conquista del Cerro de la Sal por parte de las tropas españolas no sólo interrumpiría el ciclo de repliegue iniciado en 1742 sino garantizaría un seguro avance sobre las poblaciones "bárbaras" en las regiones más orientales del virreinato: "Y siendo este gran cerro la cabeza de un numeroso gentilismo, de su descubrimiento debe probablemente esperarse la reducción de todos los bárbaros que no saben hacer uso de sus

22. Bueno, C., El Conocimiento de los Tiempos. Efeméride del año de 1767. Lima, 1767.

23. Llano Zapata, J. E., Memorias histórico, físicas, crítico, apologéticas de la América Meridional (1761). Lima 2005, p. 176. 
riquezas y al contrario, si no se rompen primero las dificultades de allanarlo, trabar sus poderosas minas y reducir a sus habitantes, apenas se logrará la conversión de las demás gentes que incultamente viven en provincias tan dilatadas que terminan con el Mar del Norte" ${ }^{\prime 24}$. A diferencia de La Condamine, Llano Zapata en su relato suprimió toda referencia a la existencia de las amazonas. Pero en cambio disertó sobre otros seres mitológicos como los tritones, las sirenas y otras "monstruosidades" humanas con el propósito de descartar sus existencias en la Amazonía al no haberlas visto nunca nadie. Sólo hizo una concesión al género fantasioso al certificar la posible existencia del "entorno dendros", un árbol mitológico supuestamente originado por un insecto.

La expedición científica integrada por los botánicos españoles Hipólito Ruiz y José Pavón, por el médico francés Joseph Dombey y por los dibujantes José Brunete e Isidro Gálvez y Gallo arribó al puerto de El Callao el 8 de abril de 1777. La misma tenía el encargo de estudiar la flora de diversas regiones de Perú y Chile con el propósito de obtener un beneficio utilitario del conocimiento metódico de dichas plantas y para que se promoviese el estudio de la botánica en ambos dominios. Ruiz y Pavón seleccionaron las regiones de Tarma y Jauja para emprender sus primeros experimentos entre mayo de 1779 y abril de 1780 . Era la primera vez que una expedición científica se adentraba a la ceja de montaña peruana para estudiar el reino vegetal aplicando el método de clasificación de Linneo. Cabe señalar que las autoridades virreinales sólo permitieron realizar ese viaje por el interior del Perú a Ruiz y a Pavón pero no a Dombey por ser súbdito francés. Muchos poblados de estas regiones estaban abandonados desde el estallido de la rebelión de Juan Santos Atahualpa y así lo hizo constar Hipólito Ruiz en un pasaje de su diario de viaje: "En otro tiempo se pensó fundar la capital del Perú en este valle de Xauxa, pero varios inconvenientes embarazaron su fundación. En el año de 1742 se sublevaron los indios de muchos pueblos ya convertidos a la fe católica y amenazaron hostilidades en esta provincia como lo ejecutaron por la de Tarma y Huanuco y se perdieron todos aquellos pueblos nuevos y algunos bastante populosos, como el de Huancabamba, Cerro de la Sal, Metrazo, Eneno, Tulumayo, Urubamba y otros"25.

Ruiz y Pavón en su recorrido por las abras, quebradas y cerros de Tarma y por las montañas de Huassahuassi y Palca lograron su propósito de practicar un inventario de numerosos árboles, arbustos, matas y hierbas, hasta ese momento sólo conocidos por los naturales de la región. En lo que se refiere a la amazonía, el repertorio de dibujos sobre las plantas de las montañas de Tarma, Jauja y Huanuco, así como el diario o relación de viaje preparado por Ruiz constituyeron los

24. Llano Zapata, Memorias histórico, p. 177.

25. Ruiz, H., Relación del viaje hecho a los reinos del Perú y Chile por los botánicos y dibujantes enviados por el Rey para aquella expedición, extractada de los diarios por el orden que Ilevó en éstos su autor (1931). Madrid, 2007, p. 142. 
primeros testimonios visuales y escritos de una región hasta ese momento considerada inhóspita y salvaje por su ferocidad humana y natural ${ }^{26}$. Pero el 1 de agosto de 1780 en el paraje montañoso de Cuchero los expedicionarios fueron víctimas de un ataque por parte de los grupos amazónicos. Ruiz exageró tal circunstancia al señalar en su diario que estuvieron "cercados de más de tres mil indios chunchos o bárbaros". La pronta huida de los científicos hacia un refugio seguro impidió una tragedia. Sin embargo, no fue este el incidente que más afectó a la expedición. El 7 de agosto de 1785 mientras exploraban las montañas de la quebrada de Chinchao, en la provincia de Huanuco un voraz incendio en la hacienda de Mácora acabó con los "equipajes, esqueletos de plantas, libros, manuscritos, bastimentos y cuantas producciones teníamos acopiadas en nuestro caserón" ${ }^{27}$. Esta pérdida supuso la desaparición de todos los diarios y cuadernos de trabajo que habían recopilado en seis años de investigación. Otro hecho lamentable fue el fallecimiento del dibujante Brunete el 16 de mayo de 1787. Uno de los logros más interesantes de la expedición Ruiz y Pavón fue que por vez se visualizaba la flora peruana a través de las imágenes que estas plantas útiles hicieron Gálvez y Gallo, Brunete y Francisco Pulgar, quien se integró al grupo en 1784 junto con el botánico José Tafalla. El proyecto era publicar un monumental repertorio de plantas bajo el título de Flora Peruviana et Chilensis, pero la edición finalmente fracasó y no vio la luz hasta el siglo XX.

\section{La visualización de la Amazonía: la expedición de Alejandro Malaspina, el Mercurio Peruano y la Relación de Gobierno del virrey Gil de Taboada y Lemus}

La frontera este del virreinato peruano experimentó un auge en su exploración en los últimos años del reinado de Carlos III. Este nuevo contexto supuso una colaboración más estrecha entre las autoridades políticas y los misioneros franciscanos. Juan Manuel Gálvez, intendente de Tarma, tuvo una actuación destacada en el apoyo de las expediciones religiosas organizadas por el religioso franciscano Manuel Sobreviela, visitador general del Convento de Ocopa, como la entrada a la montaña por la provincia de Huanta, la entrada de Chachapoyas hasta la unión de los ríos Moyobamba y Huallaga en 1790, la reconquista del valle de Vitoc o la entrada a la montaña desde el partido de Pataz. También destacó la peregrinación por los ríos Marañón y Ucayali del franciscano Narciso Girbal y Barceló en $1791^{28}$. En todos estos casos se interiorizó que el éxito de las futuras misiones religiosas estaba relacionado, simultáneamente, con la capaci-

26. Steele, A. R., Flores para el rey. La expedición de Ruiz y Pavón y la flora del Perú (17771788). Barcelona, 1982.

27. Ruiz, Relación del viaje, p. 266.

28. Amich, J., Historia de las misiones del convento de Santa Rosa de Ocopa. Iquitos. 1988, pp. 241-265. 
dad de explorar nuevas vías de penetración a la amazonía y de estimular una colonización económica y mercantil en dicha región ${ }^{29}$. Pero la visualización de la amazonía central peruana como ineludible paso previo a la recuperación territorial de esta frontera fue posible gracias a la coincidencia de tres manifestaciones claves de la ilustración tardocolonial: la expedición científica y política de Alejandro Malaspina (1789-1794), la publicación del Mercurio Peruano (17911794) por la Sociedad de Amantes del País y la redacción de la relación de gobierno del virrey del Perú Francisco Gil de Taboada y Lemus (1796).

La corbeta "Descubierta" en la que viajaba parte de la tripulación de la expedición Malaspina arribó al puerto del Callao, procedente de Chile, el 28 de mayo de 1790. La oficialidad fue alojada en la hacienda de la congregación religiosa de la Buena Muerte en el pueblo limeño de La Magdalena. Poco después arribó la corbeta "Atrevida" y su tripulación fue alojada en la casa de campo del conde de San Carlos, también en La Magdalena. Malaspina decidió que los miembros de su tripulación permaneciesen un tiempo prolongado en el Perú antes de proseguir su recorrido hacia el hemisferio norte bordeando la costa del Pacífico. Dos actividades fueron las que se emprendieron durante los meses de estancia en el Perú. La primera consistió en la sistematización de las investigaciones hidrográficas, astronómicas y geodésicas realizadas en Chile y el Río de la Plata. La segunda conllevó realizar una prolongada exploración de las regiones pertenecientes a las provincias de Lima, Tarma y Huánuco. En esta última empresa participaron los botánicos Luis Née, Tadeo Haenke, miembros de la expedición, y Juan Tafalla y Francisco del Pulgar, ambos pensionados por el virrey Gil de Taboada y Lemus. Estos cuatro personajes recorrieron entre junio y agosto los alrededores de Lima, la quebrada de Canta y las entradas a la ceja de montaña de Tarma y Huanuco ${ }^{30}$. Los conocimientos alcanzados no sólo se circunscribieron a la botánica y a la zoología como lo demuestran los dibujos realizados por Francisco Pulgar. La proeza mayor consistió en que estos naturalistas fueron los primeros ilustrados en entrar en contacto directo con las poblaciones nativas de la amazonía. Haenke y Née dejaron una serie testimonios iconográficos de la amazonía central peruana. Uno de estos apuntes titulado "Habitantes de las riberas del río Napo", apuntaba utilitariamente a registrar la posibilidad de hacer navegable a los afluentes del río Marañón ${ }^{31}$. Otros apuntes, en concreto los que Haenke tituló "Indio Iquito en la ribera del río Napo" y el "Indio Capanaguas en las riberas del río Mague" se limitaban a destacar la vestimenta de estos habitantes. Pero también Née y Haenke hicieron los

29. García Jordán, "La frustrada reconquista", p. 441.

30. Galera Gómez, A., La Ilustración española y el conocimiento del Nuevo Mundo. Las ciencias naturales en la expedición Malaspina (1789-1794): La labor científica de Antonio Pineda. Madrid, 1988, pp. 71-75; Pimentel, J., La física de la monarquía. Ciencia y política en el pensamiento colonial de Alejandro Malaspina (1754-1810). Madrid, 1998, pp. 228-230.

31. Sotos Serrano, C. Los pintores de la expedición de Alejandro Malaspina. Madrid, 1982, t. II, p. 77. 
primeros reconocimientos etnográficos de estas poblaciones a través de cartelas incluidas al pie de estos dibujos que contenía información acerca de sus costumbres. Así quedó plasmado en la serie que se conserva en la colección Bauzá depositada en el Museo de América de Madrid en donde se representa a los moradores de las riberas de los ríos Napo, Pebas, Pachitea y Putumayo, entre ellos, al indio capuchino, indio llagra, indio casibo, indio chispeo, indio yuri, indio iquito, indio guagua e indio sipibo. Esta iconografía en la que la imagen y la palabra se alternan y complementan era un recurso de explicación científica bastante utilizado en la época. Por ejemplo, la descripción etnográfica contenida en la cartela que acompaña al dibujo de un indio shipibo dice lo siguiente: "indio sipibo, havita las riveras del Ucayali: Se encuentran en esta nación muchos blancos y mugeres hermosas, según el $\mathrm{P}(\mathrm{adr})$ e Girbal. Se infiere que sean prisioneros Carapachos. Estos sipibios son tenidos por nigrománticos $\mathrm{o}$ agoreros entre aquellas naciones, los respetan estas. Adornase con vistosos y hermosos plumajes hasiendo estribar en esto y la macana armoniosamente pintada su lujo. Las mug(ere)s andan desnudas de medio cuerpo arriba" ${ }^{\prime \prime 2}$.

El texto arriba citado demuestra que los expedicionarios españoles estuvieron al tanto de las recientes exploraciones realizadas en la región central amazónica por los religiosos franciscanos Sobreviela y Girbal. Probablemente, Née y Haenke contactaron con los religiosos del Convento de Ocopa y conocieron sus planes de recolonización religiosa. Aunque esta relación no se ha podido comprobar, lo que si se puede afirmar con rotundidad es que Malaspina y los naturalistas españoles entraron en contacto con la intelectualidad limeña más representativa del momento. La Sociedad de Amantes del País, protegida por el virrey Francisco Gil de Taboada y Lemus, colaboró con los marinos y científicos de la expedición en la obtención de noticias del país que le iban a ser útiles para redactar sus informes políticos y económicos. Pero también esta circunstancia fue aprovechada por algunos ilustrados peruanos para plantear públicamente un nuevo programa relacionado con las riquezas inéditas que el Perú podía proporcionar a la monarquía hispánica en el ramo del comercio. En ese contexto es que debe entenderse el papel estratégico otorgado a la reconquista religiosa y económica de la amazonía.

El Mercurio Peruano se convirtió desde sus primeros números en un foro de discusión acerca de la utilidad de las nuevas penetraciones misioneras en la amazonía. El principal animador de este proyecto de conocimiento y rescate de una región que fue considerada como un paraje privilegiado de la naturaleza, según se afirma en el primer artículo titulado "Idea General del Perú", fue el médico Hipólito Unanue. Usando el seudónimo de Aristio, este ilustrado peruano omitió toda referencia al mito forjado alrededor de la figura irredenta de Santos Atahualpa y la imposibilidad de dominar a los "salvajes" que le secundaron. Su discurso

32. Sotos Serrano, Los pintores, t. II, p. 79. 
más bien se concentró en proporcionar una nueva representación de la amazonía como un territorio fronterizo capaz de ser dominado e incorporado a la nación gracias a un plan de colonización forjado bajo los cánones de la ilustración. Unanue resumió y divulgó en las páginas del emblemático papel ilustrado editado en Lima, sucesivamente, el origen y pérdida de las misiones de Manoa colindante con la pampa del Sacramento en la segunda mitad del siglo XVIII, la peregrinación a la región del río Huallaga del sacerdote franciscano Manuel Sobreviela en 1790, la peregrinación por los ríos Marañón y Ucayali realizada por el franciscano Narciso Girbal en 1791, la actuación de otros misioneros franciscanos con el propósito de demarcar definitivamente los cursos de los ríos Huallaga y Ucayali, la segunda peregrinación del padre Girbal a la región del Manoa en 1792 y, por último, el plan de apoyo a los religiosos por parte del gobernador de las provincias de Maynas Francisco Requena para reconquistar la región del Ucayali y la pampa del Sacramento. En todos estos artículos Unanue proyecto una retórica utópica muy en consonancia con la nueva postura adoptada por los ilustrados europeos en relación con el uso de la religión como un instrumento para estimular el progreso económico de las nuevas poblaciones. En el caso concreto de la historia natural de la Amazonía que delineó Unanue se trataba de que el gobierno virreinal amparase con medios económicos y militares la nueva oleada de exploraciones misioneras con el propósito de incorporar definitivamente a los "salvajes" y "neofitos" no sólo a la religión sino al comercio ${ }^{33}$.

Para el Mercurio Peruano el significado del repliegue de la frontera andinoamazónico fue ejemplificado a partir de la reciente extinción de las misiones franciscanas en las márgenes del río Manoa en la región norteña de Cajamarquilla o Pataz por la rebelión de las naciones de setebos, shipibos y conivos. Aristio concluía que la "pérdida de las misiones de Manoa, ha sido sensible no sólo a los padres misioneros, sino también al Perú, y hasta al mismo monarca" ${ }^{34}$. Era la primera vez que en el Perú un ilustrado asociaba el éxito de una empresa religiosa con los beneficios no sólo del virreinato sino también de la propia monarquía hispánica. El utilitarismo ilustrado permitió vincular los intereses gubernamental e imperial. Unanue se mostró interesado en destacar la contrariedad que tal retroceso supuso en la posibilidad de lograr el deseable control de la región conocida como la pampa del Sacramento, una extensa Ilanura ubicada en las márgenes del río Ucayali en la provincia de Huánuco. En sus palabras, la recuperación de Sacramento se asemejaría a una segunda conquista del Perú ya que "computando por mayor estas varias dimensiones resulta una superficie de cerca de ocho mil leguas cuadradas, en las que podrían habitar con descanso cinco millones de almas que mantuviesen con vigor el contrato y giro comer-

33. Cañizares-Esguerra, J., "La Utopía de Hipólito Unanue: comercio, naturaleza y religión en el Perú". en Cueto, M. (ed.), Saberes andinos. Ciencia y tecnología en Bolivia, Ecuador y Perú. Lima, 1995, p. 94.

34. Aristio, "Historia de las misiones de Cajamarquilla". Mercurio Peruano 51, Lima, 1791. 
cial $^{\prime \prime 35}$. Se trataba de poblar regiones geopolíticamente estratégicas para el reino en un contexto en que España y Portugal aún mantenían un diferendo por la delimitación de sus fronteras en la América Meridional. Pero también se tenía en mente otro tipo de utilidades como vincular definitivamente la costa con la selva para dar a esta última la posibilidad de "civilizarse" a partir del intercambio mercantil. Así anunciaba Unanue el significado de la peregrinación del padre Sobreviela por la vasta geografía amazónica en la que se asentaron los míticos imperios de Enim, el Paititi y El Dorado: "Las utilidades que ha producido y pueden dimanar de ella (la peregrinación) son manifiestas. Queda expedito el tránsito de Huánuco a Playa Grande, explorada la navegación del Huallaga hasta la laguna de la gran Cocama; notados los escollos y bajíos y el modo de evitarlos: y promovidos nuevos establecimientos a las márgenes del Huallaga a fin de que el viajante encuentre diariamente donde reposar y proveerse de vitualla. Por consiguiente es fácil ya la comunicación de Lima con Mainas. Se podrá entablar un mutuo comercio así con los efectos referidos, como con café, algodón de varios colores, almendra, canela, carey, incienso, añil, etc." ${ }^{136}$.

Unanue incluso resaltó las ventajas que este deseable enlace geográfico tendría para la agilización de la comunicación entre el Amazonas y Madrid. En efecto, apelando a metáforas relacionadas con la grandiosidad de los reinos de la antigüedad Aristio pronosticaba la pronta constitución de un nuevo núcleo de actividad económica en el trapecio amazónico formado por sus principales ríos y afluentes: "(en) San Joaquín de Omaguas, situado en la confluencia de los ríos Ucayali y Marañon figuraría entonces la antigua Tiro a cuyos puertos Ilegaban las naves y los frutos de todo el mundo. Por el río de las Amazonas entrarían las de la América Septentrional. Por el Pastaza y Marañón enviaría Quito sus paños y estatuas. Por el Huallaga y Mayro remitiría Lima el óleo delicioso que destilan las frondosas parras y olivas que hermosean las costas que baña el mar pacífico. Por el Apurimac, irían las pinturas y azúcares del Cuzco y el oro de Carabaya" ${ }^{\prime 37}$. Como era de esperar, nada de lo que Unanue imaginó en su utopía amazónica se cumplió ya que las entradas de los sacerdotes franciscanos Sobreviela y Girbal no produjeron el avance colonizador deseado. Pero para aquel médico ilustrado fue imperioso que este suceso quedase registrado como uno de los hechos más destacados del Perú de fines del siglo XVIII.

La relación de gobierno que el virrey Gil de Taboada y Lemus entregó a su sucesor el marqués de Osorno, Ambrosio de O'Higgins, fue concluida en 1796. Este

35. Aristio, "Peregrinación por el río Huallaga hasta la laguna de la gran Cocama, hecha por el padre predicador apostólico fray Manuel Sobreviela en el año pasado de 1790". Mercurio Peruano 59, Lima, 1791.

36. Aristio, "Peregrinación por el río Huallaga".

37. Aristio, "Peregrinación por los ríos Marañón y Ucayali a los pueblos de Manoa, hecha por el padre predicador apostólico fray Narciso Girbal y Barceló en el año pasado de 1790". Mercurio Peruano 75, Lima, 1791. 
documento oficial fue confeccionado en realidad por dos de los asesores de este gobernante, Hipólito Unanue y el contable José Ignacio de Lecuanda. La introducción de este documento titulada "Idea general del reino del Perú y sistema de su gobierno" fue responsabilidad de Lecuanda. En la misma la región amazónica peruana fue identificada con la "montaña real" y se reconoció que sus producciones en el reino animal y vegetal estaban totalmente abandonadas debido a la falta de estímulo colonizador que se derivaba del desconocimiento en estos parajes de yacimientos de oro o plata. Según Lecuanda este viejo axioma mercantilista era suficiente para explicar la ancestral impenetrabilidad de esta frontera. Pero también reconocía que la "montaña real" era infranqueable porque estaba habitada por numerosas "tribus de infieles" que se resistían a los misioneros apostólicos.

El capítulo noveno de la relación estuvo dedicado a las descripciones histórica y geográfica de esa montaña real y el estado de sus conversiones religiosas. El encargado de redactarla fue Unanue debido a la especialización que este alcanzó en dicho tema en las páginas del Mercurio Peruano. La breve descripción histórica y geográfica que hace el médico ilustrado de la amazonía muestra un territorio muy alejado de la narración mítica forjada acerca de la supuesta grandiosidad y riqueza de inexistentes imperios a los que la imaginación dio el nombre de Enim, Paititi o El Dorado. En su lugar, la descripción se concentra en destacar la presencia de innumerables y dispersas "tribus de indios salvajes" que viven entregados a la idolatría, a las borracheras y a las guerras. El gobierno virreinal reconoce tener conocimiento de veinticinco naciones entre las que destacan los Panos, Cambas, Chapeos, Arahuacas, Omaguas, Sentis, Sinabus, Mayorunas, Casibos, Carapachos y Sumirinches, que confía los misioneros "en uso de su apostólico ministerio irán exterminando, aunque muy lentamente, para disfrutar el religioso placer de reducirlos y civilizarlos ${ }^{\prime \prime 38}$. A continuación Unanue se concentra en inventariar el estado del proceso de conversión logrado por los religiosos franciscanos del colegio de Ocopa y calcula que el número de neófitos reducidos puede citarse en ocho mil dentro de la montaña real. Es en este contexto que el médico ilustrado reconoce que las campañas evangelizadoras emprendidas por los sacerdotes Sobreviela y Girbal no rindieron los efectos deseados. Pero Unanue consideraba que, al menos, debía reconocerse que con ambos franciscanos "se avanzaron las necesarias noticias, para que, repetida la diligencia, se logre el designio que tanto interesa, principalmente cuando sabemos que los portugueses se han fatigado por apoderarse de la comunicación de estos ríos y otros de la pampa del Sacramento para usurparla" ${ }^{\prime \prime 3}$. En resumen, el asalto a la amazonía desde los Andes era un asunto urgente e impostergable si se deseaba salvaguardar otra frontera geopolíticamente más importante como era la que se disputaban los dos imperios europeos con presencia en la América meridional.

38. Fuentes, M.A., (ed.) Memorias de los virreyes que han gobernado el Perú durante el tiempo del coloniaje. Tomo Sexto. Frey don Francisco Gil de Taboada y Lemos. Lima, 1859, p. 132-133.

39. Fuentes (ed.) Memorias de los virreyes, p. 139. 
Finalmente, hay un aspecto interesante que resta resaltar en la relación de gobierno del virrey Gil de Taboada y Lemus. A modo de ilustración este voluminoso documento incluyó el mapa del Perú confeccionado por Andrés Baleato, el mapa de la entrada al Marañón con el estado de sus conversiones realizado por misionero apostólico franciscano Joaquín Soler y, por último, doce dibujos de una serie de etnias amazónicas. Respecto a este último repertorio se señala en un pasaje del capítulo noveno que se consideró conveniente "dar a Vuestra Excelencia (el marqués de Osorno) un diseño en mapa de los trajes de algunos indios infieles, ya de los que me remitió el brigadier don Francisco Requena, ya de otros que me manifestó el misionero apostólico el padre Girbal, siendo éste el que más me ha instruido de sus colonias, religión, usos y costumbres" ${ }^{\prime \prime 0}$. Con relación a esto último llama la atención que estos doce bocetos de las vestimentas de los indios omaguas, carapachos, Ilaguas, sipibos, arahuacas, guayaguas, camuchimos, junis, iquitos, casibos y capanaguas, con sus respectivas cartelas, sean copias de los dibujos realizados por Tadeo Haenke para la expedición Malaspina durante su viaje por Tarma y Jauja en junio y julio de 1790. Esta coincidencia indicaría que existió un contacto al menos eventual entre Haenke, el sacerdote Girbal y el gobernador Requena, y que aquel permitió a estos dos últimos realizar copias de sus dibujos.

La historia de la divulgación de las primeras imágenes ilustradas de los habitantes de la amazonía peruana tuvo un final inusitado. José Ignacio de Lecuanda, que como se ha dicho tuvo una alta responsabilidad en la redacción de la relación de gobierno del virrey Gil de Taboada, proporcionó las copias de los dibujos de Haenke a Luis Thiebaud para que a su vez este los incluyera en el cuadro de gran formato titulado "Quadro del Perú (1799)". En esta gran obra pictórica, probablemente auspiciada por Godoy e inspirada por Lecuanda, por primera vez los habitantes de la amazonía quedaron integrados como parte de la población peruana aunque en un nivel no equivalente a los criollos, indios, mestizos y negros. En efecto, mientras los primeros eran definidos como "salvajes" estos últimos eran calificados como "naciones civilizadas". El propio Lecuanda en el texto que incluyó en el referido cuadro agregó sobre la montaña real que "esta hermosa porción del universo aunque poco conocida en sus interioridades se ha observado ser en presente la más amena, la más fecunda y rica en producciones naturales de cuantas comprende nuestro antiguo y nuevo continente. Estos amenos países están habitados de innumerables tribus de indios salvajes cuyos usos y costumbres, religión y carácter tiene no poco que admi$\mathrm{rar}^{\prime \prime 4}$. Con este gesto por parte de los últimos ilustrados del siglo XVIII la infranqueable frontera andino-amazónica en el terreno militar y religioso al menos en

40. Fuentes (ed.), Memorias de los virreyes, p. 141.

41. Barras de Aragón, F. de, "Una historia del Perú contenida en un cuadro al óleo de 1799". Boletín de la Real Sociedad Española 22 (1912), p. 237. 
lo que se refiere a la representación iconográfica experimentó un cambio en su tratamiento. Apartándose del discurso ilustrado despreciativo utilizado por La Condamine o por Ulloa, Lecuanda aventuraba la transformación de los "bárbaros" de la amazonía en útiles vasallos de la monarquía hispánica. Tal fue la última mirada que se proyectó por parte de la ilustración sobre una región cuya imperiosa reconquista se justificó desde el discurso de su utilidad.

\section{Conclusiones}

El proceso de representación de la amazonía en la segunda mitad del siglo XVIII por parte de los ilustrados experimentó una serie de variantes en el discurso y las imágenes. La percepción de la frontera andino-amazónica por ser geográficamente inaccesible y humanamente agreste fue asociada con la fantasía, la monstruosidad, la rusticidad, la barbarie y el salvajismo. Bajo ese tipo de percepción colectiva la forma de evaluarla de forma individual presentó una serie de matizaciones. La Condamine prefirió en su recorrido por la amazonía centrarse en observar, medir y describir la ruta del río Amazonas hacia el Atlántico como su contribución a la ciencia europea, poco interés le provocaron los indígenas, la flora o la fauna. Por su parte, Ulloa y Juan escribieron sus informes en la plenitud del repliegue de la frontera andino-amazónica como consecuencia de la rebelión de Juan Santos Atahualpa en 1742. El interés de ambos se concentró en proporcionar un alarmante informe político sobre los "indios chunchos" supuestamente convencidos por su líder en la necesidad de reconstruir el antiguo imperio de los incas y, por tanto, en fomentar el retorno a la barbarie de una región geopolíticamente vital para la monarquía hispánica. Por su parte, en el caso de la expedición botánica de Hipólito Ruiz y José Pavón al Perú entre 1777 y 1788 la representación de la amazonía experimentó cambios fundamentales derivados de la metodología de estos expedicionarios de observar la naturaleza, recopilar la flora y aplicar la metodología científica de Linneo. Las plantas amazónicas fueron incorporadas a la nomenclatura universal, no así los grupos étnicos que continuaron siendo tratados como salvajes. Por último, la construcción de nuevos significados desde la mirada ilustrada experimentó un salto cualitativo a fines del siglo XVIII con la coincidencia de tres exponentes de este movimiento: la expedición científica y política de Alejandro Malaspina que visitó las costas peruanas en 1790, el periódico ilustrado Mercurio Peruano editado entre 1791 y 1795 por la Sociedad de Amantes del País y el gobierno virreinal de Francisco Gil de Taboada y Lemus (1790-1796). Los tres coincidieron en visualizar una amazonía no sólo como tierra de conversión religiosa de indios bárbaros, sino como un territorio de gran potencialidad en el ámbito mercantil y un punto de avanzada estratégico en la contención de los portugueses. Por eso todos ellos coincidieron en que las futuras misiones religiosas debían servir no sólo a la difusión del catolicismo sino a la plena conversión de los "salvajes" en súbditos de la monarquía española. Uno de los 
máximos exponentes de este planteamiento utilitario fue el médico ilustrado Hipólito Unanue cuya utopía amazónica le condujo a pronosticar la inevitable transformación de esta región en un emporio del comercio mundial similar al papel jugado por la antigua Tiro en el mediterráneo. 